\title{
Meta-analysis on the efficacy and tolerability of the augmentation of antidepressants with atypical antipsychotics in patients with major depressive disorder
}

\author{
X.J. Wen ${ }^{1 *}$, L.M. Wang ${ }^{2 *}$, Z.L. Liu ${ }^{1}$, A. Huang ${ }^{3}$, Y.Y. Liu ${ }^{1}$ and J.Y. Hu ${ }^{1}$ \\ ${ }^{1}$ Department of Neurology, Sun Yat-sen Memorial Hospital, Sun Yat-sen University, Guangzhou, Guangdong Province, China \\ ${ }^{2}$ Department of Neurology, Guangdong Academy of Medical Science, Guangdong General Hospital, \\ Guangzhou, Guangdong Province, China \\ ${ }^{3}$ Cancer Center, Sun Yat-sen University, Guangzhou, Guangdong Province, China
}

\begin{abstract}
We assessed the efficacy and tolerability of the augmentation of antidepressants (ATDs) with atypical antipsychotics (AAPs) to treat patients with major depressive disorder. A retrograde study to identify relevant patient data included databases of PubMed, EMBASE, Cochrane Central Register of Controlled Trials, and Database of Abstracts of Reviews of Effects. Data from 17 trials, involving 3807 participants, were identified. The remission rate (RR) and overall response rate (ORR) of adjunctive treatment with AAPs were significantly higher than placebo treatment: $R R=1.90(95 \% \mathrm{Cl}=1.61-2.23, z=7.74$, $\mathrm{P}<0.00001)$ and $\mathrm{ORR}=1.68(95 \% \mathrm{Cl}=1.45-1.94, \mathrm{z}=7.07, \mathrm{P}<0.00001)$. We found that the short-term (4 weeks) treatment $[\mathrm{ORR}=1.70(95 \% \mathrm{Cl}=0.98-2.95, \mathrm{Z}=1.89, \mathrm{P}=0.06)]$ was significantly different from the long-term $(6-12$ weeks $)$ treatment $[\mathrm{ORR}=1.68(95 \% \mathrm{Cl}=1.45-1.94, \mathrm{z}=7.07, \mathrm{P}<0.00001)]$. No significant difference in ORR was observed between groups with or without sedative drugs. The discontinuation rate due to adverse effects was higher for adjunctive treatment with AAPs: $\mathrm{ORR}=3.32(95 \% \mathrm{Cl}=2.35-4.70, \mathrm{z}=6.78, \mathrm{P}<0.00001)$. These results demonstrate that the augmentation of ATDs with AAPs (olanzapine, quetiapine, aripiprazole, and risperidone) was more effective than a placebo in improving response and remission rates, although associated with a higher discontinuation rate due to adverse effects.
\end{abstract}

Key words: Atypical antipsychotics; Major depressive disorder; Adjunctive therapy; Meta-analysis

\section{Introduction}

The complicated symptoms associated with depression affect about $16 \%$ of the total human population during their lifetime (1). Specifically, major depressive disorder (MDD) is believed to be one of the major factors contributing to disability-adjusted life years (2). The ultimate treatment for patients with MDD is designed to not only reduce symptoms but also help patients reach and sustain remission, essential for reducing relapse and improving life quality (3-5). Although a variety of antidepressants (ATDs) are available commercially, remission is difficult to achieve for many patients with MDD as conventional ATDs only achieve remission rates from 30 to $40 \%(6,7)$.
Although conventional antipsychotics are supposed to be beneficial for MDD patients, they are not effective in relieving at least two key symptoms: loss of interest and psychomotor retardation (8). Since the application of risperidone augmentation to selective serotonin reuptake inhibitors (SSRIs) in patients with treatment-resistant depression was reported in 1999 (9), more attention has turned to atypical anti-psychotics (AAPs). Subsequently, meta-analyses showed that AAPs, augmented to ATDs for MDD patients, produced not only higher response rates but also higher remission rates $(10,11)$. Since then, new clinical trial data have emerged, including MDD subjects

Correspondence: Z.L. Liu, Department of Neurology, Sun Yat-sen Memorial Hospital, Sun Yat-sen University, Guangzhou, 510120, Guangdong Province, China. E-mail: zhonglin.liu.neuro@gmail.com

${ }^{*}$ These authors contributed equally to this study.

Received November 5, 2013. Accepted January 22, 2014. First published online June 13, 2014. 
with inadequate response to prior ATDs randomized to adjunctive treatment with aripiprazole (12-14), and especially emphasizing the short-term outcomes of AAP treatment $(13,14)$. Thus, a new meta-analysis is needed in order to further optimize the treatment for patients with MDD.

The present meta-analysis of more than 3000 MDD patients compared the remission rate, overall response rate (ORR) and discontinuation rate between AAP-treated patients and placebo-control patients. Furthermore, we compared the long-term and short-term outcomes among patients treated with AAPs, and examined whether the response rates to AAPs would be affected by sedative drugs (lorazepam, benzodiazepine and hypnotics). Overall, the purpose of this study was to evaluate the efficacy of the adjunctive strategy to treat patients with severe depression.

\section{Material and Methods}

\section{Data search}

We included all randomized, double-blind clinical trials, which compared AAP-adjunctive treatment to SSRIs/selective norepinephrine reuptake inhibitors (SNRIs) and SSRIs/ SNRIs only. Well-designed crossover-design trials were also considered. Databases included PubMed (1966-July 2012), EMBASE (1980-June 2012), CCRCT (Cochrane Central Register of Controlled Trials; to July 2012), and DARE (Database of Abstracts of Reviews of Effects; to July 2012). Reference lists of identified studies were further examined to reveal additional citations. Related conferences, annual meetings and online resources were also searched. Search terms included "olanzapine", "aripiprazole", "risperidone", "quetiapine", "major depressive disorder" and "randomized controlled trial". The search was restricted to Englishlanguage publications. The controls were placebo treatments. Detailed data including efficacy, tolerability, remission rate, response rate, and discontinuation rate due to adverse effects were carefully examined. Open-labeled trials and those with insufficient information were excluded.

\section{Patients}

The inclusion criteria for patients were: a) outpatients or inpatients aged from 18 to 65 years, b) fitting the diagnostic standard of MDD according to the Diagnosis and Statistical Manual of Mental Disorders, Fourth Edition (DSM-IV) or text revision (DSM-IV TR) diagnosis of MDD, C) single episode or recurrent MDD.

Subjects with one of the following items were excluded from the study: a) current or past diagnosis of schizophrenia, schizoaffective disorder, bipolar I disorder, or bipolar II disorder, b) post-traumatic stress disorder, c) MDD with seasonal pattern, or dissociative disorders (as defined in DSM-IV), d) female patients who were pregnant or nursing, e) borderline personality disorder, f) depression with psychotic feature, g) alcohol or substance abuse.

\section{Data selection and extraction}

Two independent researchers conducted the reviews on the identified abstracts. Trials were included if both reviewers concurred that the studies met the inclusion criteria. The numbers of patients who responded, remitted, or dropped out during the randomized phase due to adverse effects as well as the numbers of patients assigned to each treatment group were collected. If the

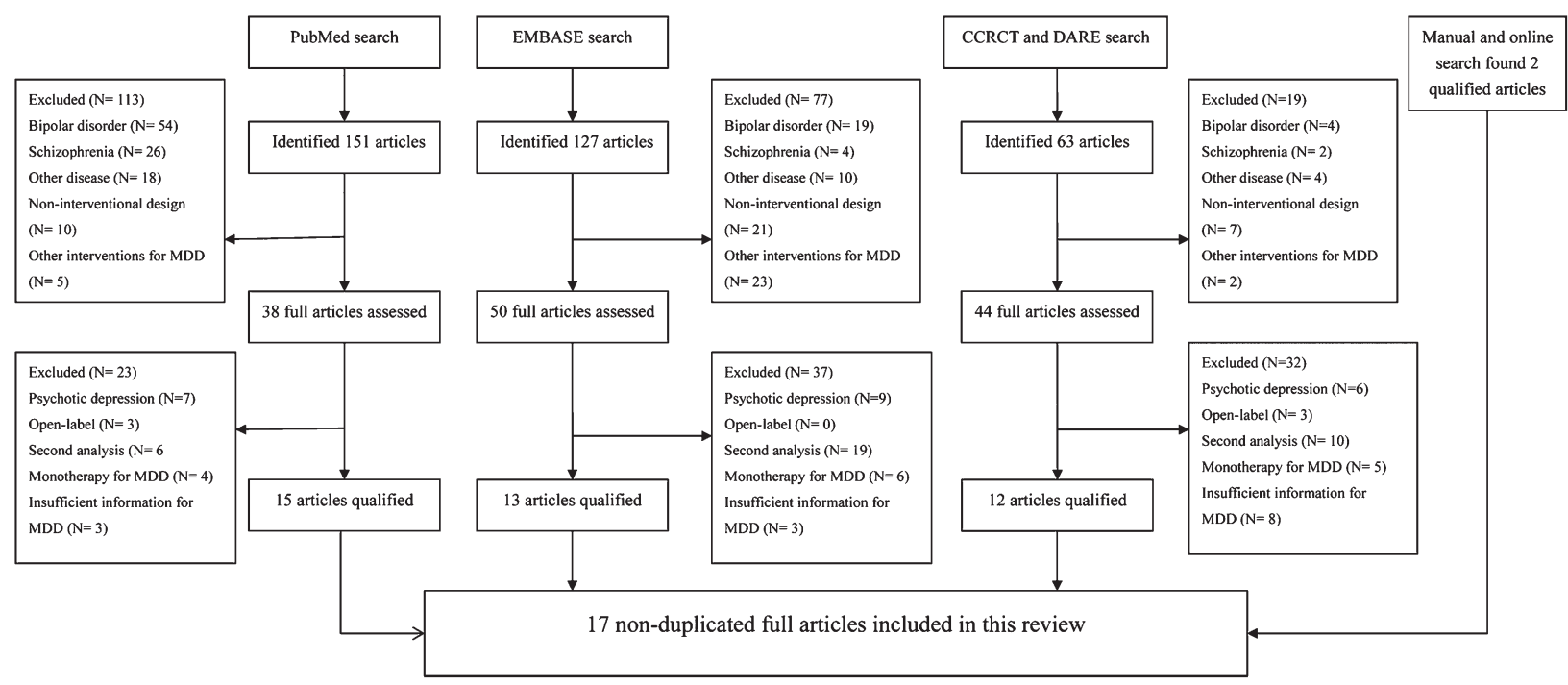

Figure 1. Flow chart of the literature search. The search was made with the terms "olanzapine", "aripiprazole", "risperidone", "quetiapine", "major depressive disorder", and "randomized controlled trial". EMBASE and other related databases were also searched with the same items produced through PubMed. CCRCT: Cochrane Central Register of Controlled Trials (to July 2012); DARE: Database of Abstracts of Reviews of Effects; MDD: major depression disorder. 
Montgomery-Asberg Depression Rating Scale (MADRS) showed scores $\leq 8$ or between 10 and 12 , data were extracted according to the main measurements.

\section{Outcome measurement}

Remission rate and overall response rate were used to assess the efficacy of AAP-adjunctive treatments. The remission scale included MADRS and the 17-item Hamilton Rating Scale for Depression (HRSD-17) $(15,16)$. Remission rate was defined according to the primary trials on the MADRS rating scale. As for the HRSD-17 rating scale, a total score of $\leq 7$ was defined as remission. Response was defined as a $50 \%$ decrease on the MADRS score from baseline to the end of study or as a $50 \%$ decrease in the HRSD-17 total score to the end of study. The discontinuation rate due to adverse effects was used to assess the safety of AAPs for MDD patients. Number needed to treat (NNT) or number needed to harm (NNH) tests (defined as the inverse of the attributable risk) were conducted to assess safety (17).

\section{Sensitivity analysis and bias assessment}

Sensitivity analysis was performed to assess the heterogeneity between subgroups in the situation of excluding small sample trials or non-randomized designed trials. According to the bias assessment of the Cochrane Handbook for Systematic Reviews of Interventions (Version 5.10), reviewers assessed the risk of bias for each eligible trial. Detailed blindness, randomization and treatment agents were presented according to the primary trials.

\section{Statistical analysis}

Statistical analysis was conducted using the SPSS 10.0 software (USA). Overall effects are reported as pooled ORRs with $95 \% \mathrm{Cl}$ and a statistically significant level of $5 \%$ $(P<0.05)$ (two-tailed) was used. Publication bias was assessed using funnel plots. Heterogeneity was evaluated by the chi-square test, with statistical significance set at $\mathrm{P}<0.1$, and the degree of heterogeneity was measured by $\mathrm{I}^{2}$. A value of $\mathrm{I}^{2}$ greater than $50 \%$ was considered to be statistically significant in terms of heterogeneity. During the data analysis, we gave priority to the OR model. If heterogeneity was detected, we turned to relative risk as an effective measure. The RevMan Version 5.1 (The Nordic Cochrane Centre, The Cochrane Collaboration, 2011, Denmark) software was applied to process these data. Attributable risk (AR), NNT, $\mathrm{NNH}$, and $95 \% \mathrm{Cls}$ were calculated according to previous studies $(18,19)$.

\section{Results}

\section{Search results}

The flow chart of the literature search is outlined in Figure 1. There were 17 non-duplicated trials that met our inclusion criteria (12-14,20-33). There was a total of 3807 participants and there were four trials on olanzapine, three

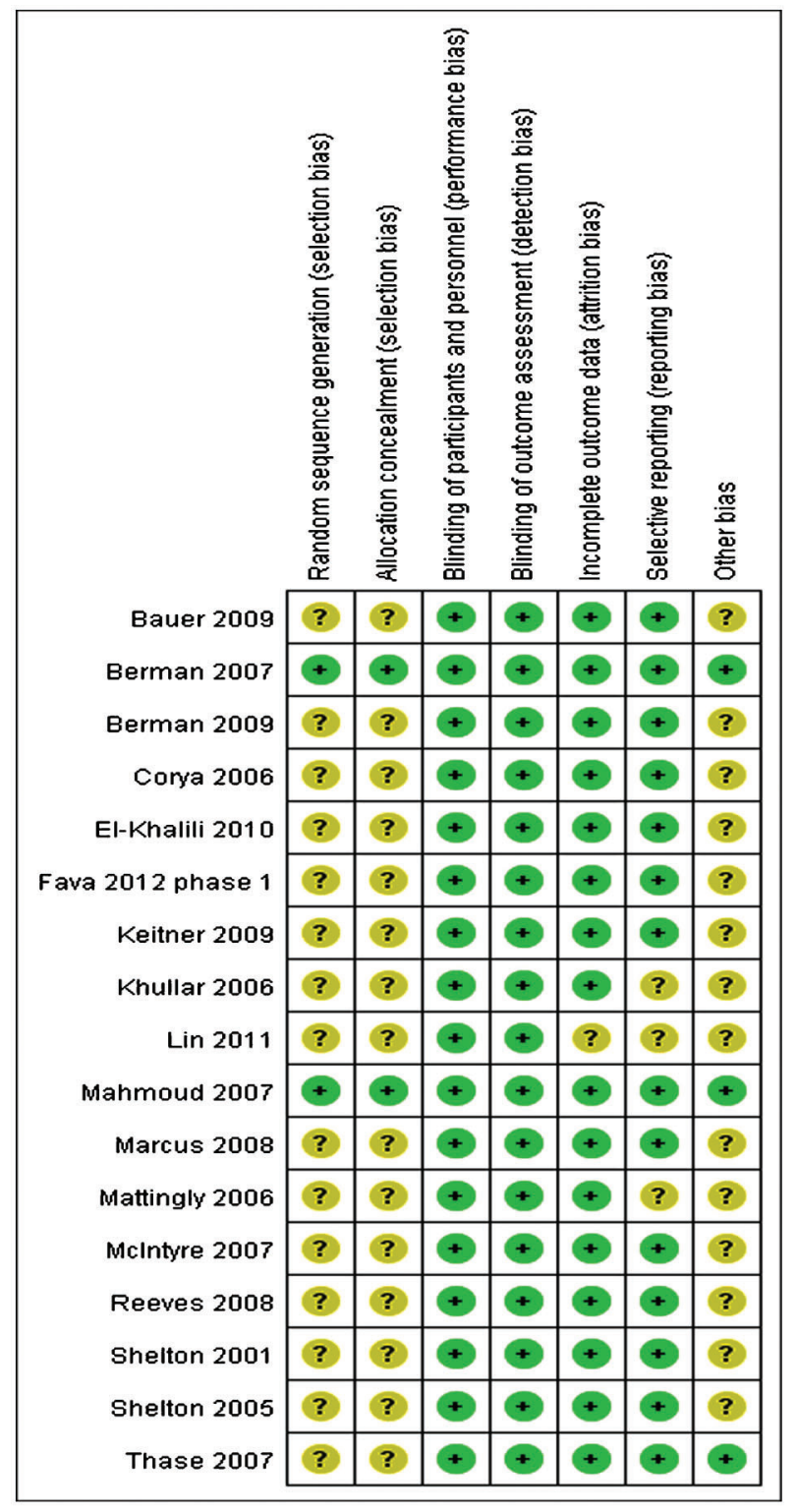

Figure 2. Assessment of risk of bias for individual trial. "?": unclear risk of bias; "+": low risk of bias. Thase et al. (29) contains two identical trials; we combined them to analyze the discontinuation rate.

on risperidone, five on quetiapine, and five on aripiprazole. No qualified reports on other AAPs such as amisulpride and clozapine were identified by manual research. Of the 17 trials, there was one trial for non-resistant depression (14), and another 16 trials were for refractory or treatmentresistant MDD. There was one trial including two identically designed studies (29). Table S1 outlines the baseline demographic data and other key information about the included trials. Figure 2 presents the summary of the risk of bias of the enrolled trials. 


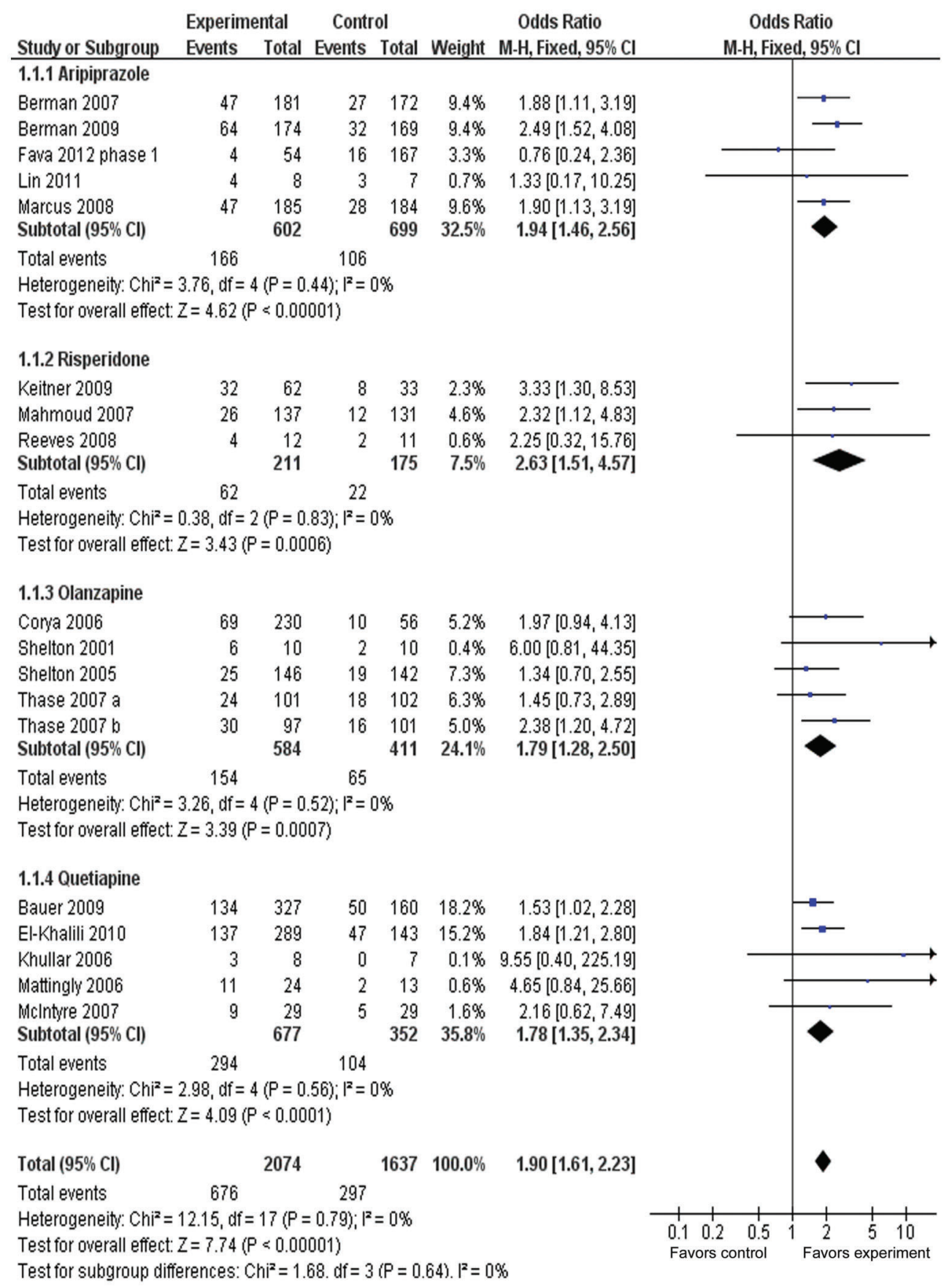

Figure 3. Meta-analysis of remission rates of adjunctive atypical antipsychotics in major depressive disorder. Odds ratios for remission on drug and placebo are grouped by types of atypical antipsychotics. Thase et al. (29) contains two identical trials. All trials were included in this subgroup analysis.

\section{Remission rate}

Figure 3 presents the remission rate between adjunctive groups and placebo groups for different types of AAPs. ORRs for different AAPs varied from 1.78 to 2.63 , with substantial overlap among $95 \% \mathrm{Cl}$. The ORR for overall remission was $1.90(95 \% \mathrm{Cl}=1.61-2.23)$, with statistical significance of $Z=7.74, P<0.00001$. The overall remission rate was $32.6 \%(676 / 2074)$ for adjunctive groups compared with $18.2 \%(297 / 1637)$ for placebo groups. The AR for remission was 0.145 , indicating an 


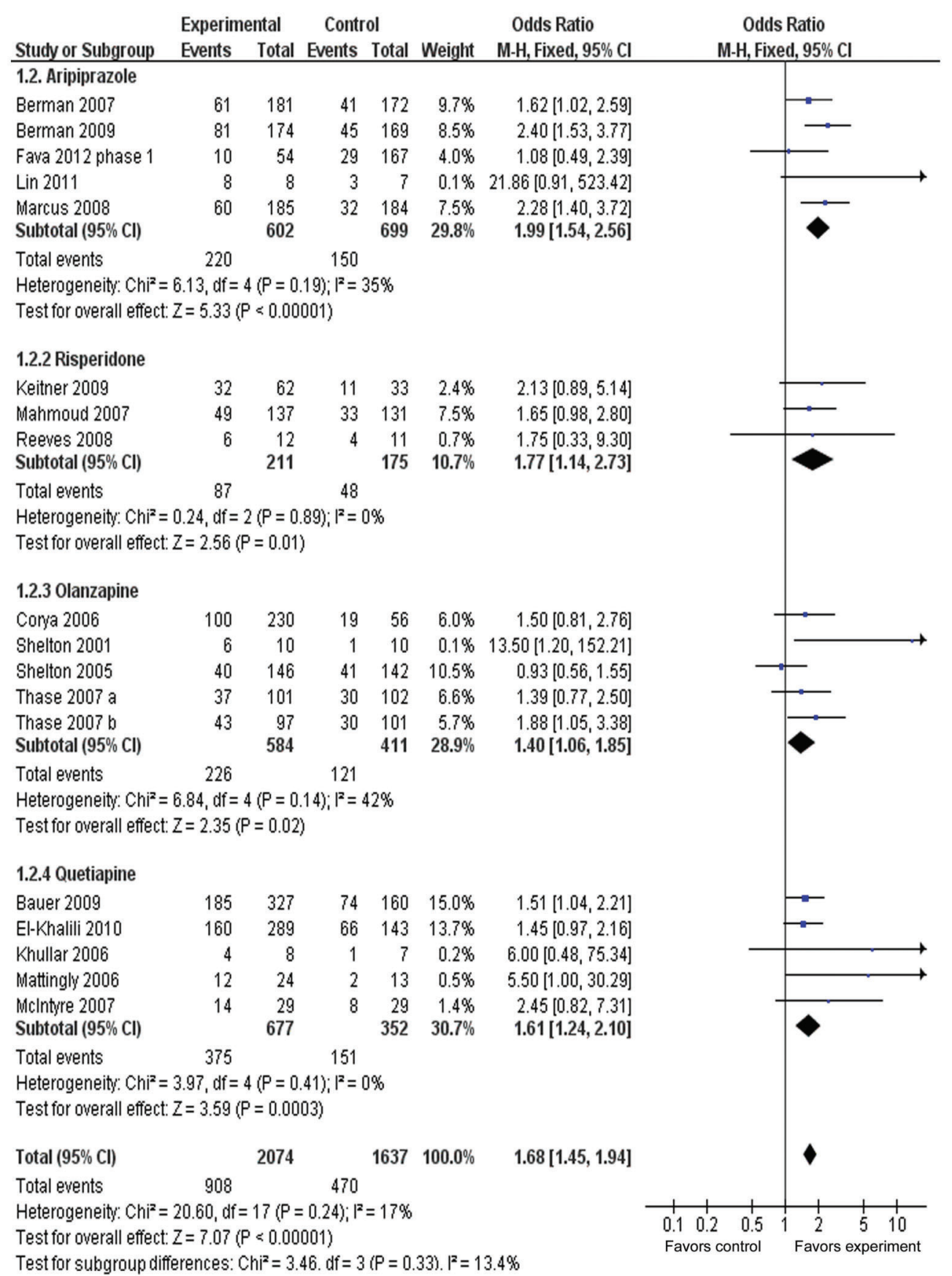

Figure 4. Meta-analysis of response rates of adjunctive atypical antipsychotics in major depressive disorder. Odds ratios for response to drug and placebo are grouped by types of atypical antipsychotics. Thase et al. (29) contains two identical trials. All trials were included in this subgroup analysis.

NNT of $7(95 \% \mathrm{Cl}=6-9)$. A test for subgroup differences indicated no significant difference: $\operatorname{chi}^{2}=1.68$, d.f. $=3$, $\mathrm{P}=0.64, \mathrm{I}^{2}=0 \%$.

\section{Response rate}

Figure 4 presents the response rate between adjunctive groups and placebo groups for different types of AAPs. ORRs for different AAPs varied from 1.40 to 1.99 , with substantial overlap among the $95 \% \mathrm{Cl}$. The ORR for overall response was $1.68(95 \% \mathrm{Cl}=1.45-1.94)$, with statistical significance of $z=7.07, P<0.00001$. The ORR was $43.8 \%$ (908/2074) for adjunctive groups compared with $28.7 \%$ 


\begin{tabular}{|c|c|c|c|c|c|c|c|c|c|}
\hline Study or Subgroup & \multicolumn{2}{|c|}{ Experimental } & \multicolumn{2}{|c|}{ Control } & Weight & $\begin{array}{c}\text { Odds Ratio } \\
\text { M-H, Fixed, } 95 \% \mathrm{Cl}\end{array}$ & \multicolumn{2}{|c|}{$\begin{array}{c}\text { Odds Ratio } \\
\text { M-H, Fixed, } 95 \% \mathrm{Cl}\end{array}$} & \\
\hline \multicolumn{10}{|c|}{ 1.3.1 short-term treatment duration } \\
\hline Fava 2012 phase 1 & 10 & 54 & 29 & 167 & $4.0 \%$ & $1.08[0.49,2.39]$ & & & \\
\hline Keitner 2009 & 32 & 62 & 11 & 33 & $2.4 \%$ & $2.13[0.89,5.14]$ & & & \\
\hline Lin 2011 & 8 & 8 & 3 & $?$ & $0.1 \%$ & $21.86[0.91,523.42]$ & & & \\
\hline Subtotal $(95 \% \mathrm{Cl})$ & & 124 & & 207 & $6.5 \%$ & $1.70[0.98,2.95]$ & & & \\
\hline Total events & 50 & & 43 & & & & & & \\
\hline \multicolumn{10}{|c|}{ Heterogeneity: $\mathrm{Ch}^{2}=3.99, \mathrm{df}=2(\mathrm{P}=0.14) ; \mathrm{I}^{2}=50 \%$} \\
\hline \multicolumn{10}{|c|}{ Test for overall effect: $Z=1.89(P=0.06)$} \\
\hline \multicolumn{10}{|l|}{ 1.3.2 long term } \\
\hline Bauer 2009 & 185 & 327 & 74 & 160 & $15.0 \%$ & $1.51[1.04,2.21]$ & & $\leftarrow$ & \\
\hline Berman $200 ?$ & 61 & 181 & 41 & 172 & $9.7 \%$ & $1.62[1.02,2.59]$ & & $\rightarrow$ & \\
\hline Berman 2009 & 81 & 174 & 45 & 169 & $8.5 \%$ & $2.40[1.53,3.77]$ & & $\rightarrow$ & \\
\hline Corya 2006 & 100 & 230 & 19 & 56 & $6.0 \%$ & $1.50[0.81,2.76]$ & & - & \\
\hline El-Khalili 2010 & 160 & 289 & 66 & 143 & $13.7 \%$ & $1.45[0.97,2.16]$ & & 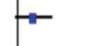 & \\
\hline Khullar 2006 & 4 & 8 & 1 & 7 & $0.2 \%$ & $6.00[0.48,75.34]$ & & & \\
\hline Mahmoud $200 ?$ & 49 & 137 & 33 & 131 & $7.5 \%$ & $1.65[0.98,2.80]$ & & 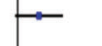 & \\
\hline Marcus 2008 & 60 & 185 & 32 & 184 & $7.5 \%$ & $2.28[1.40,3.72]$ & & $\rightarrow$ & \\
\hline Mattingly 2006 & 12 & 24 & 2 & 13 & $0.5 \%$ & $5.50[1.00,30.29]$ & & & \\
\hline Mcintyre $200 ?$ & 14 & 29 & 8 & 29 & $1.4 \%$ & $2.45[0.82,7.31]$ & & & \\
\hline Reeves 2008 & 6 & 12 & 4 & 11 & $0.7 \%$ & $1.75[0.33,9.30]$ & & & \\
\hline Shelton 2001 & 6 & 10 & 1 & 10 & $0.1 \%$ & $13.50[1.20,152.21]$ & & & \\
\hline Shelton 2005 & 40 & 146 & 41 & 142 & $10.5 \%$ & $0.93[0.56,1.55]$ & & 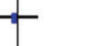 & \\
\hline Thase 2007 a & 37 & 101 & 30 & 102 & $6.6 \%$ & $1.39[0.77,2.50]$ & & مـ & \\
\hline Thase 2007 b & 43 & 97 & 30 & 101 & $5.7 \%$ & $1.88[1.05,3.38]$ & & $\rightarrow$ & \\
\hline Subtotal (95\% CI) & & 1950 & & 1430 & $93.5 \%$ & $1.68[1.45,1.95]$ & & 1 & \\
\hline Total events & 858 & & 427 & & & & & & \\
\hline \multicolumn{10}{|c|}{ Heterogeneity: Chi $^{2}=16.63, d f=14(P=0.28) ;\left.\right|^{2}=16 \%$} \\
\hline \multicolumn{10}{|c|}{ Test for overall effect $Z=6.82$ ( $P<0.00001)$} \\
\hline Total (95\% Cl) & & 2074 & & 1637 & $100.0 \%$ & $1.68[1.45,1.94]$ & & 1 & \\
\hline Total events & 908 & & 470 & & & & & & \\
\hline \multicolumn{7}{|c|}{ Heterogeneity: $\mathrm{Chi}^{2}=20.60, \mathrm{df}=17(\mathrm{P}=0.24) ; 1^{2}=17 \%$} & $0.01 \quad 0.1$ & $i$ & $10 \quad 100$ \\
\hline \multicolumn{7}{|c|}{ Test for overall effect: $Z=7.07(P<0.00001)$} & Favors control & Favors e & experimental \\
\hline
\end{tabular}

Figure 5. Meta-analysis of response rates in short-/long-term adjunctive treatment of atypical antipsychotics in major depressive disorder. Odds ratios for response to drug and placebo are grouped by short-term (4 weeks) or long-term (longer than 4 weeks) treatment duration. Thase et al. (29) contains two identical trials. All trials were included in this subgroup analysis.

(470/1637) for placebo groups. The AR for response rate was 0.15 , indicating an NNT of $7(95 \% \mathrm{Cl}=6-8)$. A test for subgroup differences indicated no significant differences: chi $^{2}=3.46$, d.f. $=3, P=0.33, \mathrm{l}^{2}=13.4 \%$.

\section{Response rate in short-/long-term duration}

Figure 5 presents the response rate in short-/long-term duration. The ORR for the short-term (4-week duration) treatment subgroup was $1.70(95 \% \mathrm{Cl}=0.98-2.95)$, showing no overall statistically significant effect $(z=1.89$, P 0.06). However, with long-term (6-, 8-, 12-week duration) treatment subgroups, the OR was $1.68(95 \% \mathrm{Cl}=1.45-$ 1.94), showing an overall statistically significant effect $(P<0.00001)$. The test for subgroup differences indicated no significant differences: $\mathrm{chi}^{2}=0.00$, d.f. $=1, P=0.96$, $1^{2}=0 \%$.

\section{Response rate in adjunctive treatment with or without sedative}

Figure 6 presents the response rate of AAPs with or without sedative. The ORR for the AAPs with sedative drugs (lorazepam, benzodiazepine and hypnotics) was 


\begin{tabular}{|c|c|c|c|c|c|c|c|c|}
\hline Study or Subgroup & \multicolumn{2}{|c|}{ Experimental } & $\begin{array}{l}\text { Contr } \\
\text { Events }\end{array}$ & $\begin{array}{l}\text { rol } \\
\text { Total } \\
\end{array}$ & Weight & $\begin{array}{c}\text { Odds Ratio } \\
\text { M-H, Fixed, 95\% Cl }\end{array}$ & \multicolumn{2}{|c|}{$\begin{array}{c}\text { Odds Ratio } \\
\text { M-H, Fixed, } 95 \% \mathrm{Cl}\end{array}$} \\
\hline \multicolumn{7}{|c|}{ 1.4.1 with concomitant medication } & & \\
\hline Bauer 2009 & 185 & 327 & 74 & 160 & $15.2 \%$ & $1.51[1.04,2.21]$ & & $\rightarrow$ \\
\hline Berman 2009 & 81 & 174 & 45 & 169 & $8.6 \%$ & $2.40[1.53,3.77]$ & & $\rightarrow$ \\
\hline Conya 2006 & 100 & 230 & 19 & 56 & $6.1 \%$ & $1.50[0.81,2.76]$ & & \\
\hline Fava 2012 phase 1 & 10 & 54 & 29 & $16 ?$ & $4.1 \%$ & $1.08[0.49,2.39]$ & & - \\
\hline Keitner 2009 & 32 & 62 & 11 & 33 & $2.4 \%$ & $2.13[0.89,5.14]$ & & \\
\hline $\operatorname{Lin} 2011$ & 8 & 8 & 3 & 7 & $0.1 \%$ & $21.86[0.91,523.42]$ & & \\
\hline Mahmoud $200 ?$ & 49 & 137 & 33 & 131 & $7.6 \%$ & $1.65[0.98,2.80]$ & & $\rightarrow$ \\
\hline McIntyre $200 ?$ & 14 & 29 & 8 & 29 & $1.5 \%$ & $2.45[0.82,7.31]$ & & \\
\hline Shelton 2005 & 40 & 146 & 41 & 142 & $10.6 \%$ & $0.93[0.56,1.55]$ & & - \\
\hline Thase 2007 a & 37 & 101 & 30 & 102 & $6.7 \%$ & $1.39[0.77,2.50]$ & & $\rightarrow$ \\
\hline $\begin{array}{l}\text { Thase } 2007 \text { b } \\
\text { Subtotal }(95 \% \mathrm{CI})\end{array}$ & 43 & $\begin{array}{r}9 ? \\
1365\end{array}$ & 30 & $\begin{array}{r}101 \\
1097\end{array}$ & $\begin{array}{r}5.8 \% \\
68.6 \%\end{array}$ & $\begin{array}{l}1.88[1.05,3.38] \\
1.61[1.35,1.92]\end{array}$ & & $\rightarrow$ \\
\hline $\begin{array}{l}\text { Total events } \\
\text { Heterogeneity: Chi } \\
\text { Test for overall effect }\end{array}$ & $\begin{array}{r}599 \\
12.57, \mathrm{df}= \\
Z=5.250\end{array}$ & $\begin{array}{l}10(P= \\
<0.000\end{array}$ & $\begin{aligned} & 323 \\
= & 0.25)_{1} 1^{2} \\
0 & 001)\end{aligned}$ & $=20 \%$ & & & & \\
\hline \multicolumn{9}{|c|}{ 1.4.2 without concomitant medication } \\
\hline Berman 2007 & 61 & 181 & 41 & 172 & $9.8 \%$ & $1.62[1.02,2.59]$ & & $\mapsto$ \\
\hline El-Khalili 2010 & 160 & 289 & 66 & 143 & $13.9 \%$ & $1.45[0.97,2.16]$ & & + \\
\hline $\begin{array}{l}\text { Marcus } 2008 \\
\text { Subtotal ( } 95 \% \mathrm{CI})\end{array}$ & 60 & $\begin{array}{l}185 \\
655\end{array}$ & 32 & $\begin{array}{l}184 \\
499\end{array}$ & $\begin{array}{r}7.6 \% \\
31.4 \%\end{array}$ & $\begin{array}{l}2.28[1.40,3.72] \\
1.71[1.32,2.21]\end{array}$ & & $\vec{v}$ \\
\hline $\begin{array}{l}\text { Total events } \\
\text { Heterogeneity: Chi } \\
\text { Test for overall effect }\end{array}$ & $\begin{array}{c}281 \\
2.03, \mathrm{df}= \\
Z=4.06(\end{array}$ & $\begin{array}{l}2 P=0 . \\
<0.000\end{array}$ & $\begin{array}{l}139 \\
36)_{1}^{2}=2 \\
\text { 01) }\end{array}$ & & & & & \\
\hline Total (95\% Cl) & & 2020 & & 1596 & $100.0 \%$ & $1.64[1.41,1.89]$ & & 1 \\
\hline Total events & 880 & & 462 & & & & & \\
\hline $\begin{array}{l}\text { Heterogeneity: } \mathrm{Chi}^{2}= \\
\text { Test for overall effect }\end{array}$ & $\begin{array}{l}14.7 ?, \mathrm{df}= \\
Z=6.63(\end{array}$ & $\begin{array}{l}13(\mathrm{P}= \\
<0.000\end{array}$ & $\begin{array}{l}=0.32 ; 1_{1}^{2} \\
0001)\end{array}$ & $=12 \%$ & & & $\begin{array}{ll}0.01 & 0.1 \\
\text { Favors experimental }\end{array}$ & $\begin{array}{c}10 \quad 100 \\
\text { Favors control }\end{array}$ \\
\hline
\end{tabular}

Figure 6. Meta-analysis of response rate in adjunctive treatment with or without sedatives. Odds ratios for response are grouped by with/without adjunctive treatment with sedative drugs, such as benzodiazepine, lorazepam, hypnotics. Fourteen trials were included in this subgroup analysis.

$1.61(95 \% \mathrm{Cl}=1.35-1.92, \mathrm{P}<0.00001)$, while ORR for the AAPs without sedative drugs was $1.71(95 \% \mathrm{Cl}=1.32-$ 2.21, $\mathrm{P}<0.0001)$, with substantial overlap among the $95 \% \mathrm{Cl}$. There were no significant differences: $\mathrm{chi}^{2}=0.14$, d.f. $=1, P=0.70, I^{2}=0 \%$.

\section{Discontinuation rate due to adverse effect}

Figure 7 presents the discontinuation rate due to adverse effects for four subgroups. The ORRs for subgroups of AAPs varied from $1.55(95 \% \mathrm{Cl}=0.63-3.83)$ to $4.85(95 \% \mathrm{Cl}=2.52-9.34)$, with substantial variation among the different agents. The ORR for discontinuation rate was $3.32(95 \% \mathrm{Cl}=2.35-4.70)$, with statistical significance of $\mathrm{P}<0.00001$. The overall discontinuation rate was $9.1 \%$
(194/2127) for AAPs groups, compared with 2.6\% (43/1680) for placebo groups. The AR for the discontinuation rate due to adverse effects was 0.07 , indicating an $\mathrm{NNH}$ of 16 $(95 \% \mathrm{Cl}=12-20)$. A test for subgroup differences showed no statistically significant differences: $\mathrm{chi}^{2}=5.05$, d.f. $=3$, $\mathrm{P}=0.17, \mathrm{I}^{2}=40.6 \%$.

\section{Publication bias and sensitivity analysis}

Funnel plots of the odds ratios for remission rate and response rate were nearly symmetric (Figure 8), while the funnel plot for the discontinuation rate appeared a little asymmetric (Figure 9). Sensitivity analysis, conducted on four excluded trials (two due to small sample size, one because of non-resistant MDD and another for crossover-design), 


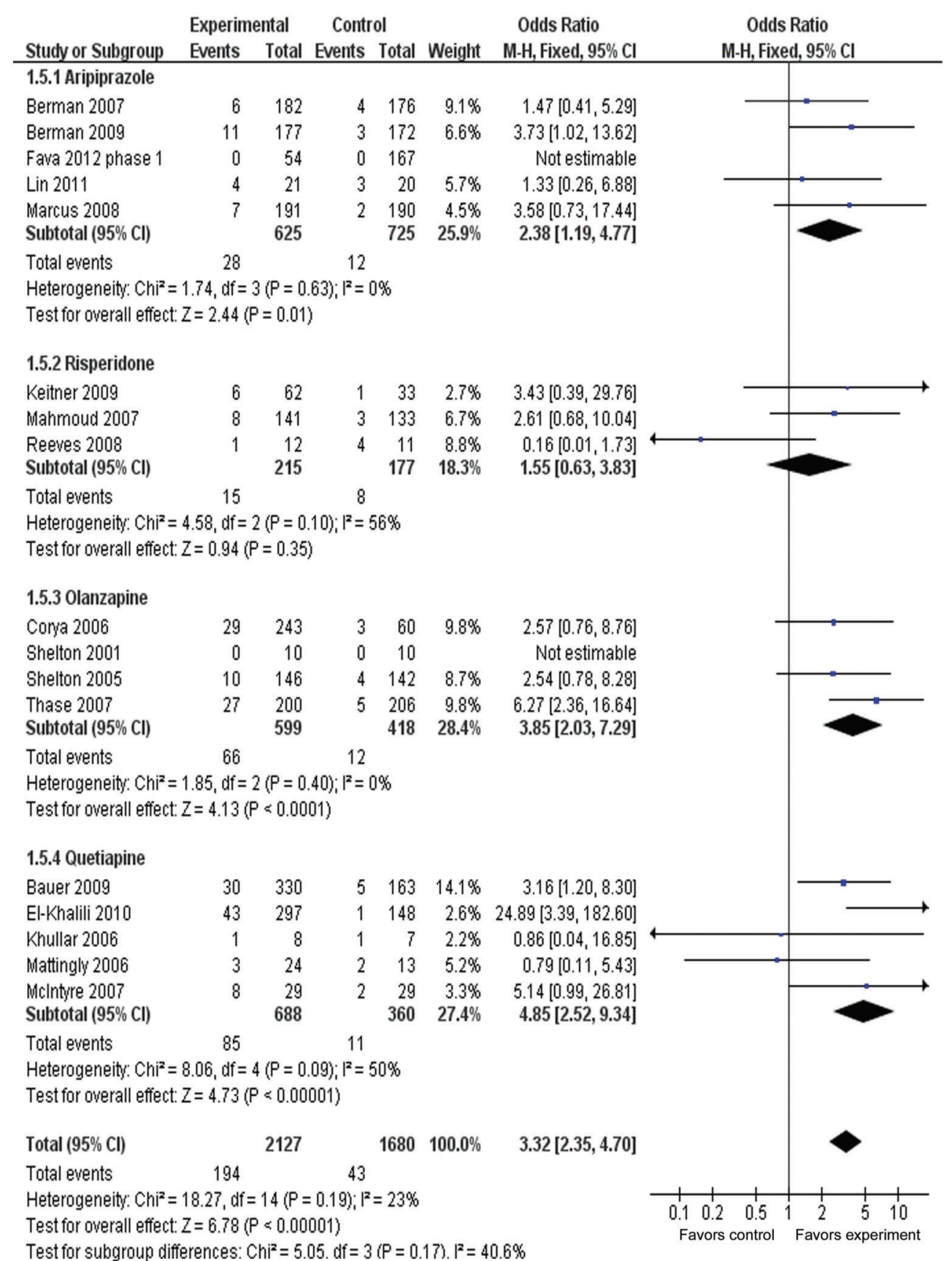

Figure 7. Meta-analysis of discontinuation rate due to adverse effect of adjunctive atypical antipsychotics in major depressive disorder. Odds ratios for discontinuation due to adverse effects to drug and placebo are grouped by different atypical antipsychotics. Thase et al. (29) contains two identical trials; we combined them to analyze discontinuation rate. All trials were included in this subgroup analysis.

showed similar results: remission $\mathrm{OR}=1.91 \quad(95 \% \mathrm{Cl}=$ 1.62-2.26, $\mathrm{P}<0.00001)$, response $\mathrm{OR}=1.66(95 \% \mathrm{Cl}=$ 1.43-1.93, $\mathrm{P}<0.00001)$, and discontinuation rate due to adverse effects: $O R=3.67(95 \% \mathrm{Cl}=2.54-5.31$, $\mathrm{P}<0.00001)$.

\section{Discussion}

As illustrated in this large-scale, randomized, doubleblind meta-analysis, the augmentation of AAPs to ATDs in MDD patients led to a higher overall remission rate as well 


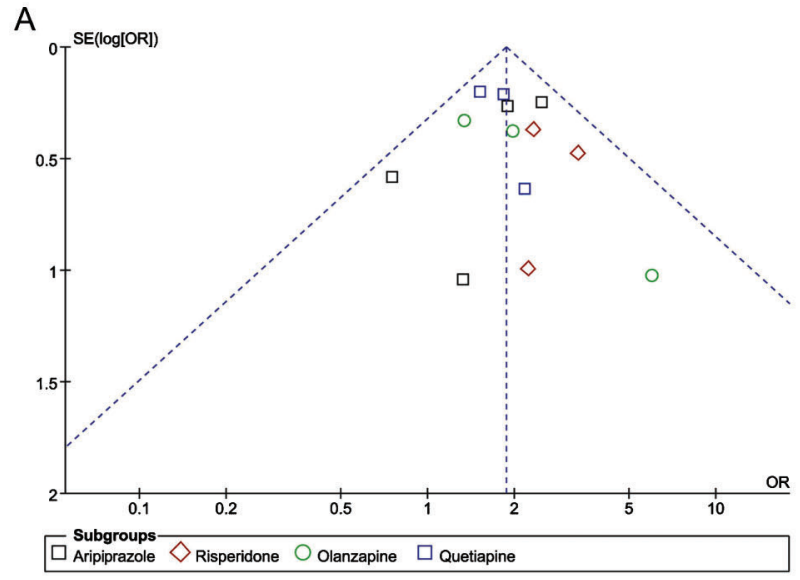

B

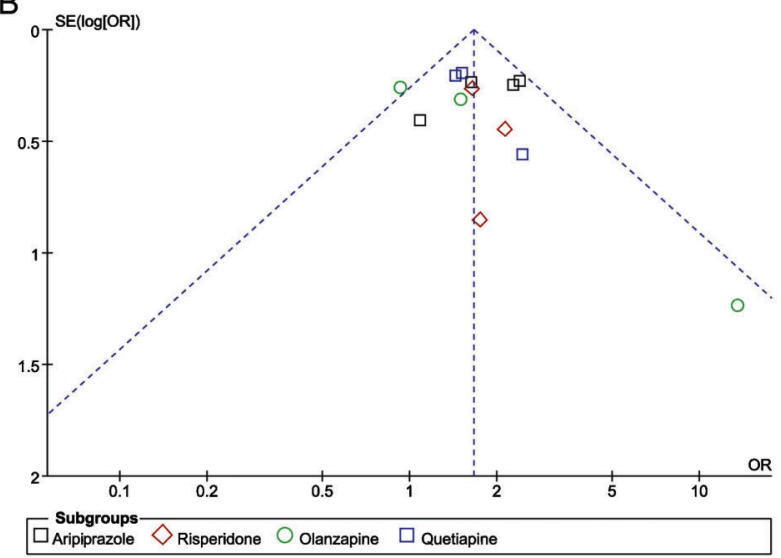

Figure 8. Funnel plot of adjunctive atypical antipsychotics in major depressive disorder for remission rate $(A)$ and response rate $(B)$. Funnel plot was the odds ratios $(\mathrm{OR})$ vs the standard error $[\mathrm{SE}(\log ) \mathrm{OR}]$ in trials.

as a higher overall response rate in the adjunctive group than in the placebo group, suggesting that patients achieved greater symptom and functional improvements in the adjunctive group than in the placebo group. In terms of remission rate, the four subgroups showed greater statistical significance in the adjunctive treatment group than in the placebo group. In addition, ORs varied little between aripiprazole, risperidone, quetiapine, and olanzapine and tests on the subgroups showed no significant difference, suggesting little difference among the four AAPs. However, a higher discontinuation rate due to adverse effects was detected in the adjunctive treatment group than in the placebo group, whose result was the same as that from a previous meta-analysis and a sequential parallel comparison design study $(10,13)$. The NNTs for remission and response rates were similar to the previous study, which only analyzed olanzapine, aripiprazole, quetiapine (for remission: 7-14; for response: 7-13) and a similar NNH for the discontinuation rate due to

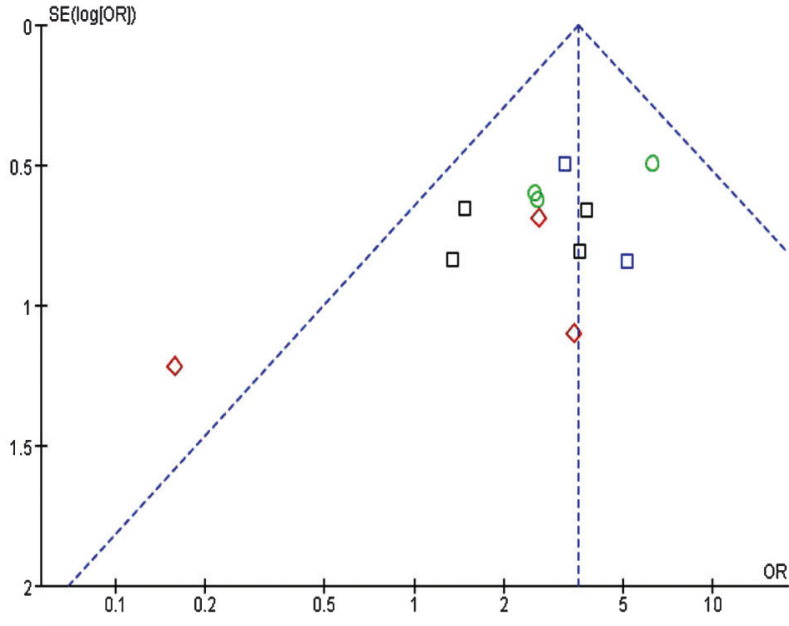

$\square$ Aripiprazole $\nabla_{\text {Risperidone } O \text { Olanzapine } \square \text { Quetiapine }}$

Figure 9. Funnel plot of adjunctive atypical antipsychotics in major depressive disorder for discontinuation due to adverse effects. Funnel plot was the odds ratios (OR) vs the standard error [SE $(\log ) \mathrm{OR}]$ in trials.

adverse effects (34). Therefore, we confirmed that AAPs could produce beneficial efficacy for MDD patients.

The new finding of the current study is that we discovered a significant difference in outcomes between long-term ( $>4$ weeks) and short-term (4 weeks) treatment periods. In the previous meta-analysis, patients treated with AAPs were divided into 4-, 6-, 8-, and 12-week duration subgroups, and no heterogeneity was found among them (11). The obvious disparity between these two studies could be explained by the fact that newly emerged clinical trials included in the current meta-analysis emphasized the recording of short-term outcomes $(13,14)$, whereas only one clinical trial did that in the previous meta-analysis. Thus, it is very important to analyze new evidence for the use of AAPs to better understand their efficacy and tolerability.

No significant difference was observed regarding the response rate of AAPs between groups with, or without, sedatives (lorazepam, benzodiazepine and hypnotics). As we all know that the AAP agents are more or less causing sedation, which may be related to the different affinities of the medications for the histamine $\mathrm{H}_{1}$ receptors (35), we may infer that the role of AAPs in MDD patients results from their sedation properties rather than their antidepressant effect, yet this conclusion needs confirmation from large well-designed studies.

We chose a 4-week duration as short-term treatment on the basis that adjunctive atypical medication would work relatively quickly in 1-2 weeks. The ORR for the 4week duration treatment subgroup was $1.70(95 \% \mathrm{Cl}=0.98-$ $2.95)$, showing no statistically significant effect $(P=0.06)$. This was not in line with the fact that most of the primary 
reports included in this meta-analysis presented a significant decrease in MADRS or HAMD-17 scores as early as 1 week. Also, the previous meta-analysis presented significant differences for the 4-week treatment $(O R=2.43$, $95 \% \mathrm{Cl}=1.01-5.85, \mathrm{P}=0.05)(11)$. However, the clinical role of the statistical significance of the 4-week treatment is uncertain due to its critical application value. Nonetheless, in terms of the 6-, 8-, and 12-week duration treatment subgroups, the response rates were superior to those of the placebo groups. A variety of reasons may account for the non-significant result for short-term treatment. Firstly, we must consider that the speed of onset is difficult to assess definitively in a clinical trial setting because of the confounding factors of early placebo response (36). Secondly, literature bias may also contribute to the lack of statistical significance in short-term treatment. Finally, some patients who do not respond after 4 weeks of medication may respond after 6-8 weeks of treatment (37), which is consistent with the results presented in the longterm treatment period, in the current meta-analysis.

For the treatment of MDD, crossover design is suitable because depression is a recurrent disease and 30-day follow-up was the same as 4-week duration treatment conducted in two trials $(14,23)$. Moreover, the two phases of the crossover-design trial included in this meta-analysis compared the same drug (13). We only extracted data from the first phase due to lack of a washout period among the two treatment phases. However, this may reduce the effect produced by the crossover-design analysis.

This meta-analysis, however, has its limitations in that one of the enrolled trials was conducted in Asia (14), while the others were from Western countries. This situation is likely to discount the representativeness of this metaanalysis and might partly account for the asymmetric

\section{References}

1. Kessler RC, Berglund P, Demler O, Jin R, Merikangas KR, Walters EE. Lifetime prevalence and age-of-onset distributions of DSM-IV disorders in the National Comorbidity Survey Replication. Arch Gen Psychiatry 2005; 62: 593602, doi: 10.1001/archpsyc.62.6.593.

2. Murray CJ, Lopez AD. Alternative projections of mortality and disability by cause 1990-2020: Global Burden of Disease Study. Lancet 1997; 349: 1498-1504, doi: 10.1016/S01406736(96)07492-2.

3. Bauer M, Whybrow PC, Angst J, Versiani M, Moller HJ. World Federation of Societies of Biological Psychiatry (WFSBP) Guidelines for Biological Treatment of Unipolar Depressive Disorders, Part 1: Acute and continuation treatment of major depressive disorder. World J Biol Psychiatry 2002; 3: 5-43, doi: 10.3109/15622970209150599.

4. Reesal RT, Lam RW. Clinical guidelines for the treatment of depressive disorders. II. Principles of management. Can J Psychiatry 2001; 46 (Suppl 1): 21S-28S.

5. Judd LL, Paulus MJ, Schettler PJ, Akiskal HS, Endicott J, Leon $A C$, et al. Does incomplete recovery from first lifetime funnel plots presented in the discontinuation rate, due to an adverse effect. In addition, as the commonly used method of intention-to-treat - last observation carried forward - ignores whether the participant's condition was improving or deteriorating at the time of dropout and instead freezes outcomes at the value observed before dropout (i.e. last observation), this inappropriately stops any decline in outcome measures and artificially stabilizes disease in dropouts. If there are more dropouts in the treatment group than in the control group, this approach will result in bias, either in favor of the treatment group if severe adverse effects are observed, or sometimes, in favor of the control group if there was no difference in adverse effects between control and treatment groups, whereas a greater proportion of patients in the treatment group have their decline artificially stabilized at an earlier stage of disease (38).

In summary, our meta-analysis indicated that augmentation of antidepressants with AAPs (olanzapine, quetiapine, aripiprazole, and risperidone) was significantly superior to the placebo treatment in both response and remission rates, but associated with higher discontinuation rates due to an adverse effect.

\section{Supplementary Material}

Click here to view [pdf].

\section{Acknowledgments}

Research supported by grants from the Chinese National Natural Science Foundation (\#81000466) and the Natural Science Foundation of Guangdong Province (\#S2013010014550 and \#S2013010014804). major depressive episode herald a chronic course of illness? Am J Psychiatry 2000; 157: 1501-1504, doi: 10.1176/appi. ajp.157.9.1501.

6. Nemeroff CB. Prevalence and management of treatmentresistant depression. J Clin Psychiatry 2007; 68 (Suppl 8): 17-25.

7. Miller IW, Keitner GI, Schatzberg AF, Klein DN, Thase ME, Rush AJ, et al. The treatment of chronic depression, part 3: psychosocial functioning before and after treatment with sertraline or imipramine. J Clin Psychiatry 1998; 59: 608619, doi: 10.4088/JCP.v59n1108.

8. Raskin A, Schulterbrandt JG, Reatig N, McKeon JJ. Differential response to chlorpromazine, imipramine, and placebo. A study of subgroups of hospitalized depressed patients. Arch Gen Psychiatry 1970; 23: 164-173, doi: 10.1001/archpsyc.1970.01750020068009.

9. Ostroff RB, Nelson JC. Risperidone augmentation of selective serotonin reuptake inhibitors in major depression. J Clin Psychiatry 1999; 60: 256-259, doi: 10.4088/JCP.v60n0410.

10. Papakostas GI, Shelton RC, Smith J, Fava M. Augmentation 
of antidepressants with atypical antipsychotic medications for treatment-resistant major depressive disorder: a metaanalysis. J Clin Psychiatry 2007; 68: 826-831, doi: 10.4088/ JCP.v68n0602.

11. Nelson JC, Papakostas GI. Atypical antipsychotic augmentation in major depressive disorder: a meta-analysis of placebo-controlled randomized trials. Am J Psychiatry 2009; 166: 980-991, doi: 10.1176/appi.ajp.2009.09030312.

12. Berman RM, Fava M, Thase ME, Trivedi MH, Swanink R, McQuade RD, et al. Aripiprazole augmentation in major depressive disorder: a double-blind, placebo-controlled study in patients with inadequate response to antidepressants. CNS Spectr 2009; 14: 197-206.

13. Fava M, Mischoulon D, losifescu D, Witte J, Pencina M, Flynn M, et al. A double-blind, placebo-controlled study of aripiprazole adjunctive to antidepressant therapy among depressed outpatients with inadequate response to prior antidepressant therapy (ADAPT-A Study). Psychother Psychosom 2012; 81: 87-97, doi: 10.1159/000332050.

14. Lin $\mathrm{CH}$, Lin SH, Jang FL. Adjunctive low-dose aripiprazole with standard-dose sertraline in treating fresh major depressive disorder: a randomized, double-blind, controlled study. J Clin Psychopharmacol 2011; 31: 563-568, doi: 10.1097/JCP.0b013e31822bb0db.

15. Hamilton M. Development of a rating scale for primary depressive illness. Br J Soc Clin Psychol 1967; 6: 278-296, doi: 10.1111/j.2044-8260.1967.tb00530.x.

16. Montgomery SA, Asberg M. A new depression scale designed to be sensitive to change. Br J Psychiatry 1979; 134: 382-389, doi: 10.1192/bjp.134.4.382.

17. Citrome L. Compelling or irrelevant? Using number needed to treat can help decide. Acta Psychiatr Scand 2008; 117: 412-419, doi: 10.1111/j.1600-0447.2008.01194.x.

18. Jaeschke R, Guyatt G, Shannon H, Walter S, Cook D, Heddle N. Basic statistics for clinicians: 3 . Assessing the effects of treatment: measures of association. CMAJ 1995; 152: 351-357.

19. Citrome L. Show me the evidence: using number needed to treat. South Med J 2007; 100: 881-884, doi: 10.1097/SMJ. 0b013e3180f63246.

20. Bauer M, Pretorius HW, Constant EL, Earley WR, Szamosi $\mathrm{J}$, Brecher M. Extended-release quetiapine as adjunct to an antidepressant in patients with major depressive disorder: results of a randomized, placebo-controlled, double-blind study. J Clin Psychiatry 2009; 70: 540-549, doi: 10.4088/ JCP.08m04629.

21. Berman RM, Marcus RN, Swanink R, McQuade RD, Carson $\mathrm{WH}$, Corey-Lisle PK, et al. The efficacy and safety of aripiprazole as adjunctive therapy in major depressive disorder: a multicenter, randomized, double-blind, placebocontrolled study. J Clin Psychiatry 2007; 68: 843-853, doi: 10.4088/JCP.v68n0604.

22. El-Khalili N, Joyce M, Atkinson S, Buynak RJ, Datto C, Lindgren $P$, et al. Extended-release quetiapine fumarate (quetiapine $\mathrm{XR}$ ) as adjunctive therapy in major depressive disorder (MDD) in patients with an inadequate response to ongoing antidepressant treatment: a multicentre, randomized, double-blind, placebo-controlled study. Int J Neuropsychopharmacol 2010; 13: 917-932, doi: 10.1017/S1461145710000015.

23. Keitner GI, Garlow SJ, Ryan CE, Ninan PT, Solomon DA, Nemeroff $\mathrm{CB}$, et al. A randomized, placebo-controlled trial of risperidone augmentation for patients with difficult-to-treat unipolar, non-psychotic major depression. J Psychiatr Res 2009; 43: 205-214, doi: 10.1016/j.jpsychires.2008.05.003.

24. Mahmoud RA, Pandina GJ, Turkoz I, Kosik-Gonzalez C, Canuso CM, Kujawa MJ, et al. Risperidone for treatmentrefractory major depressive disorder: a randomized trial. Ann Intern Med 2007; 147: 593-602, doi: 10.7326/00034819-147-9-200711060-00003.

25. Marcus RN, McQuade RD, Carson WH, Hennicken D, Fava M, Simon JS, et al. The efficacy and safety of aripiprazole as adjunctive therapy in major depressive disorder: a second multicenter, randomized, double-blind, placebocontrolled study. J Clin Psychopharmacol 2008; 28: 156165, doi: 10.1097/JCP.0b013e31816774f9.

26. McIntyre A, Gendron A, McIntyre A. Quetiapine adjunct to selective serotonin reuptake inhibitors or venlafaxine in patients with major depression, comorbid anxiety, and residual depressive symptoms: a randomized, placebocontrolled pilot study. Depress Anxiety 2007; 24: 487-494, doi: 10.1002/da.20275.

27. Shelton RC, Tollefson GD, Tohen M, Stahl S, Gannon KS, Jacobs TG, et al. A novel augmentation strategy for treating resistant major depression. Am J Psychiatry 2001; 158: 131-134, doi: 10.1176/appi.ajp.158.1.131.

28. Shelton RC, Williamson DJ, Corya SA, Sanger TM, Van Campen LE, Case M, et al. Olanzapine/fluoxetine combination for treatment-resistant depression: a controlled study of SSRI and nortriptyline resistance. J Clin Psychiatry 2005; 66: 1289-1297, doi: 10.4088/JCP.v66n1012.

29. Thase ME, Corya SA, Osuntokun O, Case M, Henley DB, Sanger TM, et al. A randomized, double-blind comparison of olanzapine/fluoxetine combination, olanzapine, and fluoxetine in treatment-resistant major depressive disorder. J Clin Psychiatry 2007; 68: 224-236, doi: 10.4088/JCP.v68n0207.

30. Corya SA, Williamson D, Sanger TM, Briggs SD, Case M, Tollefson G. A randomized, double-blind comparison of olanzapine/fluoxetine combination, olanzapine, fluoxetine, and venlafaxine in treatment-resistant depression. Depress Anxiety 2006; 23: 364-372, doi: 10.1002/da.20130.

31. Reeves H, Batra S, May RS, Zhang R, Dahl DC, Li X. Efficacy of risperidone augmentation to antidepressants in the management of suicidality in major depressive disorder: a randomized, double-blind, placebo-controlled pilot study. J Clin Psychiatry 2008; 69: 1228-1336, doi: 10.4088/JCP. v69n0805.

32. Khullar A, Chokka P, Fullerton D, McKenna S, Blackman A. Quetiapine as treatment of non-psychotic unipolar depression with residual symptoms: double blind, randomized, placebo controlled study. American Psychiatric Association Annual Meeting, Toronto, Canada. 2006.

33. Mattingly G, llivicky H, Canale J, Anderson R. Quetiapine combination for treatment-resistant depression. American Psychiatric Association 2006 Annual Meeting: New Research Abstracts. 2006; May: 20-25, Toronto; 2006.

34. Citrome L. Adjunctive aripiprazole, olanzapine, or quetiapine for major depressive disorder: an analysis of number needed to treat, number needed to harm, and likelihood to be helped or harmed. Postgrad Med 2010; 122: 39-48, doi: 10.3810/pgm.2010.07.2174.

35. Richelson E, Souder T. Binding of antipsychotic drugs to human brain receptors focus on newer generation compounds. 
Life Sci 2000; 68: 29-39, doi: 10.1016/S0024-3205 (00)00911-5.

36. Pae CU, Forbes A, Patkar AA. Aripiprazole as adjunctive therapy for patients with major depressive disorder: overview and implications of clinical trial data. CNS Drugs 2011; 25: 109-127, doi: 10.2165/11538980-000000000-00000.

37. Trivedi $\mathrm{MH}$, Rush AJ, Pan JY, Carmody TJ. Which depressed patients respond to nefazodone and when? J Clin Psychiatry 2001; 62: 158-163, doi: 10.4088/JCP. v62n0304.

38. Molnar FJ, Hutton B, Fergusson D. Does analysis using "last observation carried forward" introduce bias in dementia research? CMAJ 2008; 179: 751-753, doi: 10.1503/ cmaj.080820. 